\title{
Important Matters in Political Context
}

\author{
Byungkyu Lee, Peter Bearman
}

Columbia University

Abstract: The 2004 General Social Survey (GSS) reported significant increases in social isolation and significant decreases in ego network size relative to previous periods. These results have been repeatedly challenged. Critics have argued that malfeasant interviewers, coding errors, or training effects lie behind these results. While each critique has some merit, none precisely identify the cause of decreased ego network size. In this article, we show that it matters that the 2004 GSS-unlike other GSS surveys - was fielded during a highly polarized election period. We find that the difference in network size between nonpartisan and partisan voters in the 2004 GSS is larger than in all other GSS surveys. We further discover that core discussion network size decreases precipitously in the period immediately around the first (2004) presidential debate, suggesting that the debate frames "important matters" as political matters. This political priming effect is stronger where geographic polarization is weaker and among those who are politically interested and talk about politics more often. Combined, these findings identify the specific mechanism for the reported decline in network size, indicate that inferences about increased social isolation in America arising from the 2004 GSS are unwarranted, and suggest the emergence of increased political isolation.

Keywords: social isolation; political isolation; discussion networks; priming effects; political polarization; presidential debate

Citation: Lee, Byungkyu, and Peter Bearman. 2017. "Important Matters in Political Context." Sociological Science 4: 1-30.

Received: October 23, 2016

Accepted: October 26, 2016

Published: January 3, 2017

Editor(s): Jesper Sørensen, Olav Sorenson

Dol: $10.15195 / \mathrm{v} 4 . \mathrm{a} 1$

Copyright: (C) 2017 The Author(s). This open-access article has been published under a Creative Commons Attribution License, which allows unrestricted use, distribution and reproduction, in any form, as long as the original author and source have been credited. (0)(1)
THERE is general consensus in the public and social science community that people are more isolated today than ever before. Part of this idea arises from the broadly historical recognition that the transition to modernity is characterized by the breaking of traditional relations that bound individuals to their local communities and kinship groups. Part of this consensus is more immediate, supported by survey data that indicates that social isolation has increased and that the size of strong tie ego networks has decreased. The key set of findings in this regard are identified by McPherson, Smith-Lovin, and Brashears, whose 2006 article reports significant increases in social isolation and significant decreases in the size of Americans' discussion networks from the 2004 General Social Survey (GSS), which shows that the average size of American's immediate conversational network shrunk by a third in the two decades from 1985 to 2004.

This finding has not gone unchallenged. Critics have argued that the decrease in network size, for example, arises not because Americans are more isolated but instead as a consequence of respondent fatigue (arising endogenously during the survey) or problems occurring exogenously at the level of the survey organization. The latter-interviewer malfeasance and coding errors-are easy to dispense with as the main drivers of change. The former, whether the mechanism is seen as fatigue or respondent learning arising from order effects (where questions are located within the survey), is more difficult to reject and in fact was anticipated by McPherson et al. (2006), who raised and evaluated the impact of question order, 
training, and fatigue on self-reported discussion network size and argued that these factors had little influence. Our analysis largely supports their claims; although each critique has some merit, none precisely identify why the size of individuals' ego networks decreased. This is the task undertaken in this article.

To anticipate our argument, we start with the observation that while people report a lot of heterogeneous topics-health, finances, local events, new shows on TV, celebrity salaries, wildlife-when they describe their last important conversation (Bearman and Parigi 2004; Brashears 2014), as a rule they try to avoid potentially tense conversations. This is why we try not to get into political conversations with the parents of our children's friends at the school barbecue. Politics as a topic of conversation is fraught with potential risk, and as a consequence, while our "political matters" discussion networks are a subset of our "important matters" networks, they are systematically smaller.

But at some times, when it seems as if everyone is talking about politics, people do talk about politics. In the United States, politics becomes especially salient in election years and even more so around key moments. Some of those key moments are local—for example, primaries. But others are national; for example, the first debate of the presidential candidates following their party conventions. When these events take place, people are primed to think about politics and this priming shifts the ways in which they interpret the "important matters" name generator used by the GSS to capture core strong tie networks. When political matters are primed, reported network size decreases for the simple reason that people talk with fewer people about politics than they do about "important matters" more generally. One of the surprises of the 2004 GSS (in which smaller interpersonal networks were first observed) is that the survey-in contrast to previous administrations-took place in the fall of a presidential election year. This turns out to be critical.

\section{Roadmap}

Immediately below, we briefly review the extended debate precipitated by the 2004 GSS with respect to increased social isolation in America. This debate centers on methodological issues because increased isolation was not associated with any theoretically relevant social changes in the initial publication. We suggest that political priming allows us to see how political polarization expresses itself on network size. We then consider the relationship between partisanship and network size over time to show how temporally polarized contexts matter. Priming can be political or apolitical, and one way to think about priming effects in surveys is to consider attention cycles. We show how incredibly short such cycles are using Google Trends data for the fall of 2004. We then use a Bayesian change point model to identify the moment of sharpest change in reported network size over the course of the 2004 GSS survey period. This coincides with peak attention to the first presidential debate. We show that the priming effect of the debate-the closer to the debate, the smaller the network size reported-does not suffer from reachability or prominence bias. Against that background, we consider how priming and context interact by focusing on polarization within the GSS primary sampling units. Finally, we discuss the implication of our findings. 


\section{Increasing Social Isolation as Methodological Artifact?}

The idea that there were potential exogenous drivers of decreased network size was first proposed by Fischer (2009), who suggested that a random technical errorindividuals who should have been reported as missing were reported as having zero discussion partners-artifactually induced the core findings. There was some truth to the first part of this claim: after Fisher's critique, the National Opinion Research Center (NORC) announced that 41 cases that had been coded as reporting zero confidants should have been treated as missing data (Fischer 2009:658). While there was a coding error (Fisher was right), the error had no effect on the results (McPherson, Smith-Lovin, and Brashears 2009). The observation, first proposed by Paik and Sanchagrin (2013), that some interviewers may have overrepresented isolated individuals - presumably so as to get through their interview more quicklyappears to be similar. Some interviewers are associated with overreporting isolates, but it is highly unlikely that this actually matters (cf. Appendix A in the online supplement).

The idea that isolation is an artifact of order effects is more challenging. Here, the mechanisms are varied. One idea is that-similar to the so-called overreporting interviewers-respondents wanted to end the survey more quickly and so didn't report talking with others about important matters. This may be because they learned (from within the survey) that if they identified an organization that they were a member of, a host of questions about that organization followed. So here, fatigue and learning as mechanisms overlap. Of course, respondents in 2004 may have experienced many more surveys of all sorts in which they were trained to expect "follow-up questions" to any answers they gave. Fatigue on its own may have played a role. In some of the 2004 GSS administrations, the social network questions were placed at the end of the already excessively long 90-minute face-toface interview.

Throughout this debate, two separate outcomes-proportion isolated and decreasing network size-were often conflated. The various mechanisms proposed as (artifactually) inducing the observation of network change matter differently for each outcome. For example, McPherson et al. (2009) show that while the coding errors may necessarily impact network size, the extent of that impact is minor. Similarly, they acknowledge that coding errors do influence (slightly) the extent of social isolation, writing, for example "[W]e are pretty sure that there are inflated zeros in both 1985 and 2004, and we are pretty sure that there are more in 2004 than in 1985" (2009:674). For McPherson et al., the picture is messy, but the conclusions they draw are the same-they observe a meaningful decrease in network size.

Using the positional variation in the social network modules in the 2010 GSS, Fischer (2012) suggests that the 2004 GSS network size decreases may be explained by training effects arising from question order. We tend to think about training effects as negative effects, but they need not be. If surveys can get respondents to think of specific contexts-family, neighborhood, school-they can be "trained" to recover more names in response to a "name generator." In this sense, as Brashears (2011) shows, "training" conceptualized as "priming" can lead to more rather than fewer nominations. Against this background, it is not surprising that Bras- 
hears (2011) shows that the question-order effect-whether an extensively long battery of voluntary organizational membership questions, each with follow-ups, preceded the network name generator-is observable on network size but not on social isolation. That said, correcting for order effects indicates that much of the observed decrease in network size remains poorly understood—although likely a consequence of priming rather than fatigue. Brashears' work has shifted the focus of debate to decreases in network size where change is marked and not well understood.

In sum, with respect to the various methodological challenges to the increased isolation hypothesis, we can simply say that after a number of years of such challenges, the core result—-decreased network size—remains a bit elusive. Why should we care? Obviously, if the effect is real-that is, if there is no methodological smoking gun-then McPherson et al. $(2006,2009)$ have empirically identified a really important social fact about America, one anticipated in the literature, perhaps most forcefully by Putnam (2000) but articulated in reference to a wide variety of contexts (Parigi and Henson 2014). And if that is what happened, then it means that we have to pay more attention to understanding the substantive changes that must also have happened in America from 1985 to 2004-and beyond - that restructured the nature of our closest interpersonal networks.

\section{Did We Miss Big Historical Changes?}

It is not as if McPherson et al. (2006) didn't think about the kinds of big historical changes that might have been operating. Others have followed suit. We can partition the candidate historical factors into three broad groups: demographic, technological, and social. It makes sense, as McPherson et al. (2006) first argued, that demographic shifts in American society could lead to the increasing social isolation: for example, "As the population gets older and more racially diverse, we would expect networks to get smaller, since older people and racial minorities have smaller networks, on average" (p. 367). These candidate changes and othersincreased inequality, work hours, racial diversity, and proportion of the population living alone-did not drive changes in network size (McPherson et al. 2009). In fact, demographic stability and the absence of any relationship between the modest change that was observed led Fischer (2009) to think that there had to be a coding error of some sort in the first place, because for something real to change, some real change has to cause it.

With respect to interpersonal networks, it seems almost obvious that the internet and social media have changed the way people communicate, thereby reshaping the ways in which people relate to each other (Hampton and Ling 2013; Hampton, Sessions, and Her 2011; McPherson et al. 2006, 2009; Parigi and Henson 2014; Sigman 2009). One argument is that the proliferation of new communication channels arising from technological change makes it easier to maintain weak ties with otherwise disconnected alters and that this could reduce the number of alters reported when people are asked to name their close (that is, strong tie) confidants as in the GSS. But all the evidence suggests the opposite (Hampton et al. 2011; Wang and Wellman 2010; Zhao 2006) — the use of new technology is positively associated 
with network size. In any case, the argument is basically anachronistic. Facebook, for example, was launched in February 2004. When the GSS was in the field, it had fewer than 1 million members and was not open to the public. The online social network/Internet revolution hadn't happened.

The body of scholarship focused on increasing social fragmentation broadly captures the obvious social changes salient for interpersonal networks. Independent of segregation dynamics, one strand of the social fragmentation hypothesis focuses on the way in which people organize their relationships. Here, the idea is that the changing patterns of associational life may have an implication for network size. Less civic engagement and participation in community activity reduces opportunities to interact with others, thereby leading to decreases in network size (McPherson et al. 2006, 2009; Putnam 2000; Wellman 1979). This is a good idea, but empirically, neither the level of informal social participation nor the extent of associational membership changed significantly between 1985 and 2004 (Marsden and Srivastava 2012; Paxton 1999; Schwadel and Stout 2012). One can imagine that the relationship between voluntary associational memberships and network size changed over this period, but this is not the case. The correlation between the number of voluntary association memberships and the number of confidants is almost identical over the same time period (McPherson et al. 2009). Thus, reduced opportunities for social interaction arising from the loss of community does not explain the smaller networks reported in 2004.

The loss of community thesis also invokes increasing segregation across diverse demographic traits, most notably race, ethnicity, and class (Fischer and Mattson 2009). At the limit, increasing segregation in contexts in which the number of potential interlocutors is fixed (as it is in the GSS) inevitably leads to a decrease in network size (Rytina and Morgan 1982). But this limit is not even approximated empirically, and while spatial and residential segregation has increased across all of these traits, McPherson et al. (2006) and later Smith et al. (2014) show that within the GSS strong tie network, the extent of network homogeneity across different demographic dimensions is remarkably similar from 1985 to 2004 after accounting for changes in population composition.

Critically, for us, increased attitudinal segregation, often thought about as political polarization, has been largely ignored. As we show subsequently, increased polarization-a form of social fragmentation-drives network size declines but only at specific moments and most acutely for specific individuals. The key to the puzzle of "for whom and at what times" hinges on how name generators work.

\section{The "Important Matters" Name Generator}

The "important matters" name generator has a distinguished provenance. It has been repeatedly instrumented in network surveys and is believed to capture the core of one's interpersonal strong tie network (Burt 1984; Marsden 1987; McPherson et al. 2006) despite a long history of criticism since its introduction in the 1985 GSS (Bailey and Marsden 1999; Bearman and Parigi 2004; Fischer 1982; Marin 2004; Paik and Sanchagrin 2013; Small 2013). Defenders have long noted that the network characteristics obtained through the "important matters" name generator do not 
significantly differ from those obtained from differently worded name generators such as "strong tie", "emotionally close tie," or "significant people" (Mollenhorst, Völker, and Flap 2008; Straits 2000). But even if similar network characteristics (e.g., homophily or network density) are observed across diverse name generators, one cannot infer that these name generators capture network ties that are actually important to respondents. In his study of an online survey of more than 2,000 Americans, Small (2013), for example, found that half of the people talk about important matters with nonimportant alters, and almost half of the important alters are not included in ego's core discussion networks. Small concluded:

"The core discussion network is not a representation of our strong ties; it is a combination of the people we are close to, people we are not close to but who are knowledgeable about the matters we regularly find important, and people we are not close to but who are available because of our routine activities" (2013:481).

It has also been long known that the topics people report talking about when they respond to the "important matters" (or similar) name generator consist of variety of important and trivial topics including, "cloning headless frogs" (Bearman and Parigi 2004), "my husband's affair with my sister" (Small 2013), and "KFC changing the color of their bucket" (Brashears 2014). It is not necessarily that respondents are vacuous: As Brashears argues, people discuss seemingly trivial topics because they "are important simply because they are issues that concern those who are important to us" (2014:506). What matters to most people (and their interlocutors) are topics that are right in front of them, temporally-topics that enter into our issue-attention cycle (Downs 1972). For brief periods of time, people care about natural disasters, mass shootings, or dishonest politicians. These topics are, under normal conditions, what flows through networks generated by "emotionally close," "significant," or "important matters" name generators ${ }^{1}$. The social and political contexts in which the important matters name generator is given matter not only by shaping what is talked about but who one talks with. If the "important matters" name generator induces different ideas about what is important, because of the timing of the survey-and what is immediately within the respondents' attention cycle-those topics influence who comes to mind. The really unusual thing about the 2004 GSS, in contrast to earlier and later GSS administrations, is that it took place in the fall of a presidential election year.

\section{Issue-Attention Cycles during the 2004 Presidential Election Period}

If the salient issue is not particularly contentious and/or positions on that issue are not highly polarized (for example, very few people do not genuinely feel sad when natural disasters occur, and even hardened gun advocates are upset-or indicate such—when children are gunned down by a mass shooter), people feel free to talk about the issue with many others. But highly contentious and polarized issues are different. People only talk about contentious issues with people they feel safe sharing their opinion with (Gamson, Fireman, and Rytina 1982). By the fall of 
2004, the political polarization we now take for granted in the United States had largely solidified (Abramowitz and Saunders 2008; Fiorina and Abrams 2008) ${ }^{2}$, with network effects that encouraged homophilious group formation to avoid partisan dissonance (Baldassarri and Bearman 2007; Huckfeldt and Sprague 1987, 1988). To a great extent, Americans are now sorted along partisan lines and discuss politics with like-minded people. An interesting and important consequence is that people who are not yet sorted in political discussion networks are increasingly segregated.

We know that people's interpretation of the important matters name generator is strongly subject to survey context (Brashears 2011; Eagle and Proeschold-Bell 2015; Small, Deeds Pamphile, and McMahan 2015). From Downs (1972), we know that attention cycles are short. Salient events attract public attention and shape the interpretative context but only for short periods of time. It follows, then, that events that channel public attention to politics channel the topics that come to mind in response to the important matters name generator to political matters. If the issue-orienting event is political, then the important matters people discuss will be more likely to be about political matters than, say, disasters. It turns out that this is easily testable.

Panel A in Figure 1 shows the issue-attention cycle from September to December 2004 based on Google Trends data. In the fall of 2004, while people searched for specific things at different times, their attention to any given issue was short lived. Here, we can see bursts of interest in hurricanes, CSI, the presidential debate, the flu, the (Boston) Red Sox, the presidential election, and finally turkey, presumably for Thanksgiving dinner ${ }^{3}$. Panel B shows how frequently people searched for one of the two main presidential candidates (Bush and Kerry) over the same period. It is reasonable to assume that the frequency of Google searches for the presidential candidates tracks the publics' attention to and interest in political matters (broadly construed) during the election period. The search volume for both Bush and Kerry peaked the day after the election (November 3rd). Not surprisingly, the second largest search volume occurred the day after the first presidential debate (October 1st). The sharp peaks in public attention reported in panel B show that these two events are obviously salient with respect to political matters. We focus on the first presidential debate in our study ${ }^{4}$.

\section{The Sharp Moment of Intense Priming: The First Presidential Debate in 2004}

Earlier we noted that under normal conditions, people talk about the issues that are important to them-issues that are front and center in their attention cycle. When the important matters name generator is asked is itself important. The fact that the 2004 GSS was in the field during the presidential election provides us with a unique opportunity to see how timing matters.

We tend to think that years are homogeneous temporal units, but obviously, with respect to the ways in which temporal context shapes respondents, they are heterogeneous. Consider 2004. The 2004 GSS was administered from August 18th to January 3rd. When the survey was first fielded, almost a month had passed since the Democratic Convention that formalized the nomination of John Kerry, 

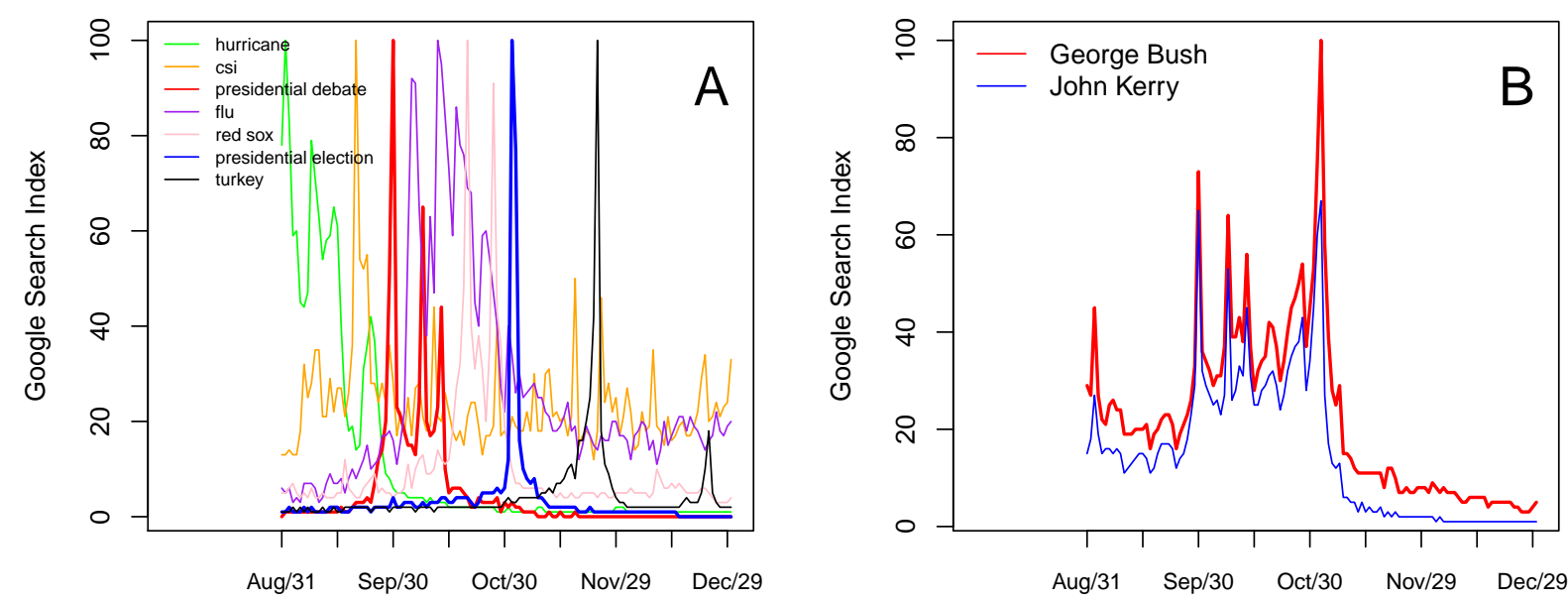

Figure 1: Issue-attention cycles in the fall of 2004 based on Google Trends analysis. Note: The Google search index, obtained by Google Trends analysis, shows the share of queries for the search keyword with respect to the total volume of queries for each particular keyword within four months (September 1st through December 31st) in the United States. In panel A, the maximum query share in the specified time period is normalized to be 100 for each search term during the period. Therefore, the meaningful comparison is between different moments in time within a particular search and not between different searches within a particular moment in time.

whose competition (Dean and Clark) was especially hapless, at least electorally. The Republican Convention that formally nominated George Bush was yet to occur. For most Americans, political issues were less salient in the dog days of summer than spending some time working on their tan on the beach or getting their kids ready for school. But this quiescence changed, most markedly in the days surrounding the buildup towards (and fallout from) the first presidential debate on September 30th.

On September 30th, six weeks into the fieldwork with twelve weeks to follow, over 62 million people-more than at any time since 1980 and more than would watch at any time until 2012-watched the first presidential debate (Kenski and Stroud 2005). The election-and political matters specifically-were front and center in the issue-attention cycle for the brief period before and after the debate. If priming matters, which it does, then the first presidential debate defines the context for important matters as, well, "political matters" (Benoit, Hansen, and Verser 2003).

Political scientists have been asking Americans about their discussion networks for years using a GSS name generator strategy that differs in only one respect from the 2004 survey; instead of asking about "important matters" they ask about "political matters" (Huckfeldt, Johnson, and Sprague 2004; Zuckerman 2005). The networks that they induce in response to this name generator are always smaller than those that arise from the important matters name generator ${ }^{5}$. So, if the debate 
primed respondents to think about important matters as political matters, then we ought to anticipate that their networks-for the short period of time in which the political context occupied their attention cycle-were smaller. This turns out to be the case.

Given temporal heterogeneity with respect to both polarization and political priming, we would not expect the reported declines in network size to be the same across the whole survey period. Just as we observe temporal variation in polarization, we can observe marked spatial variation at the level of GSS primary sampling units. Net of time, some counties are more polarized than others, and we would anticipate that spatial polarization shapes respondent reports. Thus, the local temporal and spatial context with respect to polarization is critical to understanding how respondents responded to the important matters name generator. Tying all these pieces together requires thinking about how local context, priming, name generators, and individual social networks intersect.

\section{Who Talks to Whom about What, When, and Where?}

Who talks to whom about what (important matters or political matters), when and where is the key issue we need to solve. Temporal priming events, like the presidential debate, will manifest themselves more for more political individuals. Individuals who are largely nonpolitical will be less sensitive to a prime like the presidential debate because that prime will not lead them to change the topics they consider important. At the same time, these kinds of temporal priming events filter through local contexts, and their effects are thus shaped by the structure of that context-that is, the opportunities that people embedded within them have for finding and reporting on discussion partners (Huckfeldt and Sprague 1987). A central feature of those contexts, for us, is the extent to which they are segregated, or polarized ideologically. In some ways, the answer about local context is simple: where everyone agrees with one another, priming events (like watching a debate) will not lead to risky conversations. Where there is a lot of disagreement, people will avoid talking about matters that would allow for that disagreement to arise (Gerber et al. 2012). They could talk about the weather, and they could think that the weather was "important," but the prime shifts their framework. They know that the weather is not important and that politics is important, and the reality is that they talk to fewer people and report that fact.

In highly polarized environments, where individual networks are segregated, network homophily is high and so people discuss whatever topics they discussincluding political matters-with like-minded people (Baldassarri and Bearman 2007). In such contexts, people are aware that they agree with one another. Thus, priming has little influence. However, in less polarized environments, where individual networks are intermingled with respect to the partisan identity, people know they may disagree with one another and so to avoid political confrontations, they selectively talk about other topics (Cowan and Baldassarri 2016). In such settings, the priming effect has a large influence.

As the summer of 2004 ended and thinking about tans gave way to thinking about politics, discussion networks around politically important matters in an 
increasingly polarized America became increasingly shut down. This happened more in communities with low levels of polarization than in communities that were already highly polarized. Political priming has a more intense suppression effect on conversations in which ideological segregation is less pronounced because it is in those settings that people eschew potentially contentious conversations. In highly segregated communities, this effect is weaker.

\section{Data and Methods}

We use the GSS egocentric network data arising from the "important matters" name generator collected in 1985, 1987, 2004, and 2010 and the American National Election Studies (ANES) "political discussion" network data collected in 2000 and 2006. The 1985, 1987, and 2010 GSS surveys were fielded in the spring and summer of nonpresidential election years. The 2004 GSS and 2000 ANES data were collected during presidential election years, though the 2000 ANES was collected after the election. ANES collected both "important matters" and "political matters" data in 2006, in telephone interviews, as part of survey experiments during the fall of the midterm election year. The GSS data and the 2000 ANES data arise from an in-person interview.

The dependent variable is discussion network size, measured by the number of alters invoked by the network name generators. The questions about name generators used in each survey are similar but not precisely the same. Network size ranges from zero to six in the "important matters" name generator in the GSS data, but the maximum number of alters in the "political matters" name generator is four in the 2000 ANES and 10 in the 2006 ANES data. For comparability, we top-code network size of ANES data at six, although our results become stronger without top-coding.

The 2000 ANES asked:

From time to time, people discuss government, elections and politics with other people. I'd like to ask you about the people with whom you discuss these matters. These people might or might not be relatives. Can you think of anyone? IF LESS THAN 4 NAMES MENTIONED, PROBE: "Is there anyone else you talk with about these matters?"

The 1985 GSS and 2004 GSS asked:

From time to time, most people discuss important matters with other people. Looking back over the last six months-who are the people with whom you discussed matters important to you? Just tell me their first names or initials. IF LESS THAN 5 NAMES MENTIONED, PROBE: "Anyone else?"

The 2006 ANES pilot study asked:

During the last six months, did you talk with anyone face-to-face, on the phone, by email, or in any other way about [things that were important 
to you / government and elections], or did you not do this with anyone during the last six months? What are the initials of the people who you talked with face-to-face, on the phone, by email, or in any other way during the past six months, about [things that were important to you / government and elections]? RECORD UP TO 10 NAMES. AFTER EACH NAME, "Who else?" UNTIL UNPRODUCTIVE OR THREE NAMES ARE ENTERED.

\section{Analytic Strategy}

We employ diverse strategies to show how priming mechanisms suppress core discussion network size in the 2004 GSS data. First, we show how much of the daily variance of network size is attributable to interview timing. To account for the fact that our dependent variable is generated by a count process, we employ random-intercept poisson regression models treating the date of survey as a level 2 unit across the ANES and GSS data. We assess the significant presence of daily variance using likelihood ratio tests (Rabe-Hesketh and Skrondal 2012). Identifying significant daily variation is an essential step towards establishing that survey timing matters, especially in the 2004 GSS data.

Next, we situate the 2004 GSS data in broader political context to show how political polarization and partisanship interact across two decades. We pay special attention to the 2000 ANES data that collected political discussion networks right after the election period as a useful point of comparison to the 2004 GSS data. Following McPherson et al. (2006, 2009)'s strategy, we estimate zero-inflated poisson regression models to handle the overdispersion of core discussion network size. Our independent variable in this analysis is party identification. By comparing the difference in differences of network size between partisans (Republicans or Democrats) and nonpartisans (Independents) across periods characterized by different levels of political polarization, we can identify how nonpartisans are less likely than partisans to talk about important or political matters, depending on political context. In the statistical models, we include standard demographic characteristics known to be related to network size such as age, years of education, sex, race, marital status, working status, and the number of children as pretreatment control variables, which would not affect party identification. All variables' wording and coding are presented in Table B1 in the online supplement.

We then we shift our attention to priming within the 2004 GSS data. The entire survey period in 2004 was highly political because of the polarized presidential election, but the level of political priming peaked sharply (as shown in Figure 1) in the period around the first presidential debate. That debate is the treatment of our analysis. The date of the interview is our instrument to explore the effects of political events (i.e., the first presidential debate) on reported network size. We largely follow the lead of other recent studies that employ a regression discontinuity design to compare the mean before and after a particular date, treating events as exogenous random shocks leading to differential responses (Hoffman and Bearman 2015; Legewie 2013). 


$$
\begin{aligned}
& T=\left\{\begin{array}{l}
0 \text { if respondent } i \text { was interviewered before the event } \\
1 \text { if respondent } i \text { was interviewed after the event }
\end{array}\right. \\
& T=t_{0} \text { if the respondent } i \text { was interviewed at } t_{0} \text { days before or after the event }\left(t_{0}>0\right)
\end{aligned}
$$

As in Equation (1), the treatment indicator in prior studies is whether each respondent is interviewed after the event occurs. However, we are interested in the pattern of change before and after an event, given that the event focused on in this article - the first debate-is one of a class of events that are anticipated by our respondents. Our expectation is that as the GSS interviews approach the date of the first presidential debate, people will report fewer discussion partners. Likewise, as the debate recedes out of the issue-attention cycle, respondents will report larger discussion networks. We model this V-pattern around the first presidential debate by estimating the effect of the elapsed time from the day of the event within moving calipers. Rather than assume pre-fixed duration effects, we employ continuous treatment indicators as a linear indicator in Equation (2). This enables us to report the full range of all treatment effects for all (theoretically plausible) moving calipers ${ }^{6}$.

Of interest is the width of the caliper both before and after an event because we do not know a priori how long the debate exerts its influence. To address this issue, we need to ascertain the probability of change in network size at each point in time during whole period. We employ a Bayesian change point model to estimate the probability of observing a sharp change in daily network size using the $b c p$ package in $\mathbf{R}$ (Erdman and Emerson 2007). To account for the different number of daily participants across time, we first do a partial pooling using a random intercept regression model and predict the random intercept (i.e., mean) for each day. From this we estimate the posterior probability of change points and their posterior means using the default tuning parameters recommended by Barry and Hartigan (1993), with a burn-in period of 5,000 draws and mcmc size of 200,000. The maximum width of the caliper is defined by the two contiguous change points with the second greatest posterior probabilities arising from the Bayesian change point model.

We first show a smoothing line by fitting the local regression (i.e., local polynomial regression fitting) to identify trends of network size as a nonparametric method using the loess function in $\mathbf{R}$ package. For statistical tests, we run a simulation to identify how likely it is that we can observe significant effects by chance alone, which is preferable to conventional statistical null hypothesis testing given the bias-efficiency tradeoff with regard to the width of moving calipers. Specifically, using poisson regression models for network size, we estimate the debate effect on the simulated data sets by randomly permuting the survey date of each participant 1,000 times while all other individual characteristics, including network size, are fixed. Our simulation strategy induces a situation in which the number of respondents watching the first debate is the same but those who watch the debate are different. Differently put, those who watch the debate in a given period are compared to those who watch it in a randomly assigned period. 


\section{Potential Threats for the Identification of Debate Effects}

We assume that interview timing is exogenous to survey participation. However, a potential threat to our identification strategy might originate from reachability bias. For example, if for some reason those who participate in the survey around the debate are more likely to be less educated or unmarried, average network size around the debate will be smaller not because of the debate per se but because those less educated and/or unmarried have smaller networks. To test for possible bias, we first compare characteristics of the sample during the treatment period $\left(t_{0}\right)$ to the rest of period. In doing so, we calculate student $t$-statistics of mean difference between the two periods, with survey weights adjusted for pretreatment variables associated with survey participation for both interviewers and respondents.

Specifically, we include variables that were utilized as controls in prior studies (Fischer 2009; McPherson et al. 2006, 2009; Paik and Sanchagrin 2013). For respondents, these include age, sex, education, race, marital status, working status, number of children, party identification, and partisan strength. For interview context, these include interview length, SAQ skip, uncooperativeness, and poor comprehension. For interviewers, these include interviewers' sex, age, race, and tenure. See Table B1 in the online supplement for variable wording and coding.

The model we use rests on the assumption that the first presidential debate is exogenous to other political events (i.e., the temporal stability assumption) (Legewie 2013:1208) and that it was the most salient event driving network size during the sample period. To test the assumption, we examine the potential presence of other salient event effects by presenting all plausible effects of different moving calipers $\left(t_{0}\right)$ across the whole survey period. A final concern is the linearity assumption underlying the usage of linear treatment indicators. We know that social realities are complex; for example, one can imagine that debate effects are latent until three days and suddenly take place at the fourth day. But the power of linear modeling lies in its simplicity. We test the linearity assumption by comparing one random intercept poisson model with linear indicators against another with a series of dummy indicators within each moving caliper using likelihood ratio tests. As we will show, the model is robust to these three threats.

\section{Interactions with Political Engagement and Geographic Polarization}

As discussed earlier, the priming mechanism through which the presidential debate drives how people interpret the "important matters" name generator should be more salient for those who are more politically engaged or living in more polarized neighborhoods. We would expect that their responses are quicker than the other and thus show a steeper V-pattern. We assess the sensitivity of different subgroups with respect to the debate by fitting a loess curve across each subgroup.

With respect to individual characteristics, we utilize two variables to measure the level of political engagement-political discussion frequency and political interest. We dichotomize them into high engagement (discuss politics often or are very interested in politics) and low engagement. As for the neighborhood context, we measure the degree of political polarization in each Primary Sampling Unit (PSU) in three different ways. First we consider the proportion of people who identify 
as moderates on the seven-point political ideology scale in the GSS. Where this proportion is above the mean, the PSU is considered nonpolarized. Second, we measure the kurtosis of the same political ideology scale ${ }^{7}$. When kurtosis is below the mean, polarization is coded as present. Finally, we measure party sorting by the correlation between political ideology and party identification. When that correlation is above the mean, the community is treated as polarized.

\section{Results}

The important matters name generator is sensitive to time because what people consider important-and therefore with whom they report discussing important matters-is driven by issue-attention cycles. Table 1 reports network size based on GSS data (in 1985, 1987, 2004, and 2010) and ANES data (in 2000 and 2006), with survey weights adjusted. The central puzzle is the huge decrease in ego network size from 2.92 in 1985 to 2.14 in 2004.

Comparison with results from ANES-which employs the "political matters" name generator-provides support for the idea that people discuss political matters when they talk about "important matters" in politically contested periods. From Table 1 it is evident that the proportion of social isolates reported in political discussion networks is always larger than that reported in "important matters" discussion networks, except for in the 2004 GSS. A survey experiment conducted within the 2006 ANES data confirms the significantly smaller size of political discussion networks compared to important matters discussion networks ( 2.14 versus $2.74 ; p=$ 0.052). It may be a coincidence that the size of the 2006 political matters discussion network produced precisely the same estimate for network size as the 2004 GSS, but it suggests that the shrunken size of the important matters networks reported in 2004 arises from political priming, which reframes "important matters" to "political matters".

We examine the degree to which network size varies across survey dates based on likelihood ratio tests using a random-intercept poisson model without covariates. This model reveals that across all GSS surveys, daily network size variation is largest and significant in $2004\left(\chi^{2}=19.438, p\right.$ value $\left.<0.001\right)$. Importantly, we observe a negative correlation between daily variance and average network size ( $r=$ $-0.46)$. The absence of significant daily variation observed in the other GSS surveys supports the idea that what people construe as important matters is relatively stable in contexts that are not explicitly political. The significant daily variation in 2004 suggests that something unusual happened at the end of September.

\section{The Effect of Increasing Political Polarization across Decades}

It is always the case that nonpartisan respondents report talking to fewer people than partisan respondents about important or political matters. Some set of the topics of conversation induced by the important matters name generator are political (Bearman and Parigi 2004; Brashears 2014), and as one would expect, people without political attitudes talk less about political matters than those who do have attitudes (Huckfeldt et al. 2004). Priming, which shifts the framework of the name 
Table 1: Network size and its daily variations during survey period across different datasets.

\begin{tabular}{|c|c|c|c|c|c|c|c|}
\hline & \multicolumn{2}{|c|}{ GSS } & \multirow{2}{*}{$\begin{array}{c}\text { ANES }^{\mathrm{e}} \\
2000\end{array}$} & \multirow{2}{*}{$\begin{array}{l}\text { GSS } \\
2004\end{array}$} & \multicolumn{2}{|c|}{ ANES 2006 pilot $^{\mathrm{f}}$} & \multirow{2}{*}{$\begin{array}{l}\text { GSS } \\
2010\end{array}$} \\
\hline & 1985 & 1987 & & & moduleA & moduleB & \\
\hline Name Generator ${ }^{\mathrm{a}}$ & $i m p$ & $i m p$ & pol & $i m p$ & pol & $i m p$ & $i m p$ \\
\hline$\%$ of Social Isolation & 0.10 & 0.06 & 0.28 & 0.22 & 0.38 & 0.28 & 0.13 \\
\hline \multicolumn{8}{|l|}{ Network Size } \\
\hline Mean ${ }^{b}$ & 2.94 & 2.50 & 2.29 & 2.14 & 2.14 & 2.74 & 2.42 \\
\hline SD & 1.77 & 1.28 & 2.34 & 1.82 & 2.18 & 2.27 & 1.77 \\
\hline $\mathrm{N}$ & 1,531 & 1,800 & 1,551 & 1,426 & 346 & 316 & 1,272 \\
\hline Survey Period & spring & spring & winter & fall & winter & winter & summer \\
\hline \multicolumn{8}{|l|}{$\%$ Variations across days } \\
\hline Daily variance $^{\mathrm{c}}\left(\sqrt{\psi_{11}}\right)$ & 0.002 & 0.000 & 0.074 & 0.169 & 0.445 & 0.244 & 0.059 \\
\hline$\chi^{2}$ & 0.001 & 0.000 & 2.497 & 19.438 & 45.422 & 31.377 & 0.538 \\
\hline p-value ${ }^{d}$ & 0.489 & 0.500 & 0.057 & 0.000 & 0.000 & 0.000 & 0.232 \\
\hline
\end{tabular}

Notes:

a Name generators are denoted "imp" for "important matters" and "pol" for "political matters."

$\mathrm{b}$ Throughout, mean network size is calculated by top-coding network size at 6.5 with sampling design adjusted as is conventional.

${ }^{\mathrm{c}}$ It is estimated by random-intercept poisson regression models without any covariates using $x t p o i s s o n$ in Stata.

d Log-likelihood tests are performed to examine whether daily variances are statistically significant.

e ANES 2000 probed up to four discussion partners, but here we present the mean of top-coded network size. Without top-coding, it is 1.79 .

${ }^{\mathrm{f}}$ In an ANES 2006 pilot study based on a telephone survey, one half of survey respondents were randomly assigned to a "political/election" name generator (module A), and the other half were assigned to an "important matters" name generator (module B).

generator from "important matters" to "political matters," suppresses partisans and nonpartisans equally, and so-absent any other factor-we would expect to observe consistent differences in network size. We can see these processes unfold in Figure 2, which reports the average network size of nonpartisan and partisan respondents. Figure 2 reports mean network size for respondents who identify as independents with respect to party identification in comparison to all others who are leaning towards or identify themselves as partisan (either Democratic or Republican) across a series of studies in which network data were collected from 1985 to $2010^{8}$. Across the board, nonpartisan respondents have fewer discussants. The largest difference is observed in 2004, when political polarization is highest (Abramowitz and Saunders 2008; Fiorina and Abrams 2008) - precisely because the 2004 GSS was uniquely administered in the fall of a presidential election year.

Recall that our expectation was for no difference, absent any other factor. But there is an additional factor-polarization. Political priming in the context of political polarization drives network size further down. Table 2 reports results from zero- 


\section{Network Size by Party Identification}

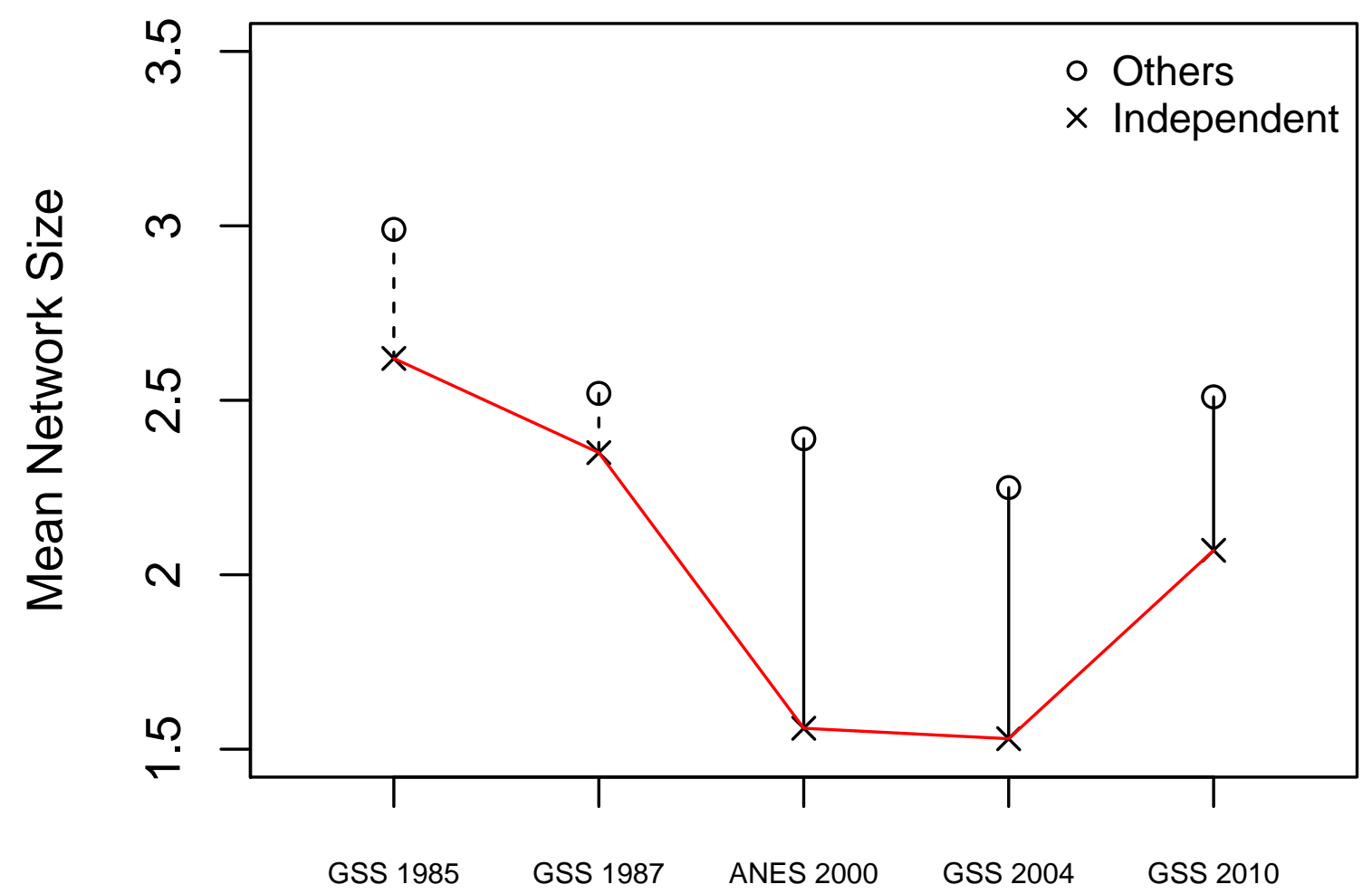

Figure 2: Differences of mean network size by party identification across sample surveys. Note: Each $X$ represents the average network size among those who identify themselves as independent on the party identification scale, and each circle represents estimates among other members excluding the independent category. Statistically significant differences between the two are plotted as a solid line, otherwise as a dotted line.

inflated poisson regression models controlling for standard social-demographic variables that are associated with network size-age, sex, years of education, race, marital status, number of children, and working status (also see the full regression table in Table B2 in the online supplement). Note that zero-inflated poisson regression models simultaneously take account for the poisson process of counting the number of alters as well as the zero-inflation process, in which an inflated zero is modeled given the expected number of zeros from the poisson process.

First, we can observe significant declines in nonpartisans' network size from 1985 and 1987 (also 2000 and 2010) to 2004 across both model frameworks after accounting for the zero-inflation process. The key period is 2004. In 2004, nonpartisans talk about important or political matters less than any other period. At 
Table 2: The difference in differences of network size between partisans and nonpartisans across time with reference to the 2004 GSS data.

Panel A. Zero-inflated poisson regression models among nonpartisan sample.

\begin{tabular}{lcrrr}
\hline Reference Year $=$ & 1985 & 1987 & 2000 & 2010 \\
\hline Count Model Coefficients (Poisson with log link) & & & & \\
Year $=2004$ & $-0.554^{+}$ & $-0.462^{\dagger}$ & $-0.324^{*}$ & $-0.356^{+}$ \\
& $(0.086)$ & $(0.083)$ & $(0.129)$ & $(0.084)$ \\
\hline Observations & 393 & 440 & 412 & 429
\end{tabular}

Panel B. Zero-inflated poisson regression models among all sample.

\begin{tabular}{lcccc}
\hline Reference Year $=$ & 1985 & 1987 & 2000 & 2010 \\
\hline Count Model Coefficients (Poisson with log link) & & & & \\
Party ID = Independent & -0.029 & -0.034 & -0.049 & -0.108 \\
& $(0.062)$ & $(0.047)$ & $(0.078)$ & $(0.075)$ \\
Year = 2004 & $-0.252^{\dagger}$ & -0.067 & -0.025 & 0.004 \\
& $(0.037)$ & $(0.034)$ & $(0.050)$ & $(0.035)$ \\
Year (2004) $\times$ Party ID (Independent) & $-0.300^{\dagger}$ & $-0.313^{\dagger}$ & $-0.251^{*}$ & $-0.216^{*}$ \\
& $(0.099)$ & $(0.090)$ & $(0.108)$ & $(0.094)$ \\
\hline Observations & 2,900 & 3,167 & 2,913 & 2,612 \\
\hline
\end{tabular}

Note: We estimate zero-inflated poisson regression models on network size after controlling for respondent's age, sex, education, race, marital status, the number of children, and working status (see Table B2 in the online supplement for full regression tables). The 2000 ANES data investigate the network size up to four, and so we also top-coded network size of the 2004 GSS data as four in this comparison, but the results are the same without top-coding.

Standard errors are in parentheses. ${ }^{*} p<0.05,+p<0.01$.

the same time, the difference in network size between partisan and nonpartisan voters in 2004 is statistically much larger than at any other time. These descriptive results suggest that network size (the number of people individuals discuss things with) depends on an interaction between characteristics of people and the broader temporal context. In this case, a priming that transforms "important matters" into "political natters" suppresses network size for everyone. So does polarization, on its own. But when political polarization is high, nonpartisan individuals report talking to others even less. They eschew potentially contentious conversations.

\section{The Priming Effect of the First Presidential Debate}

Figure 3, panel A reports the number of survey respondents in each day. Before the election, roughly 15 people took the survey each day; after the election, roughly five people took the survey each day. Given the small number of observations around and after the election, we explore the temporal patterns of network size variation a month before and after the first presidential debate. Panel B reports-using a 
Daily Participants

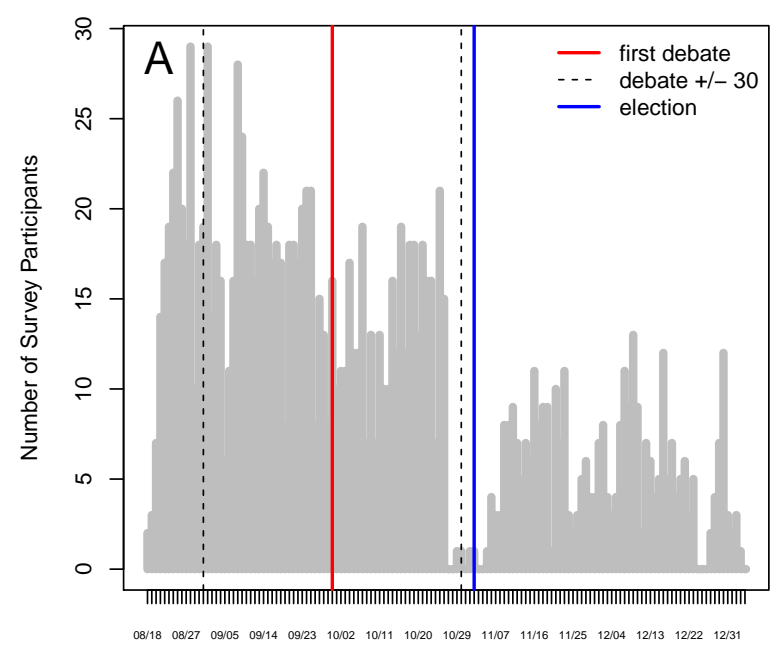

Survey Date

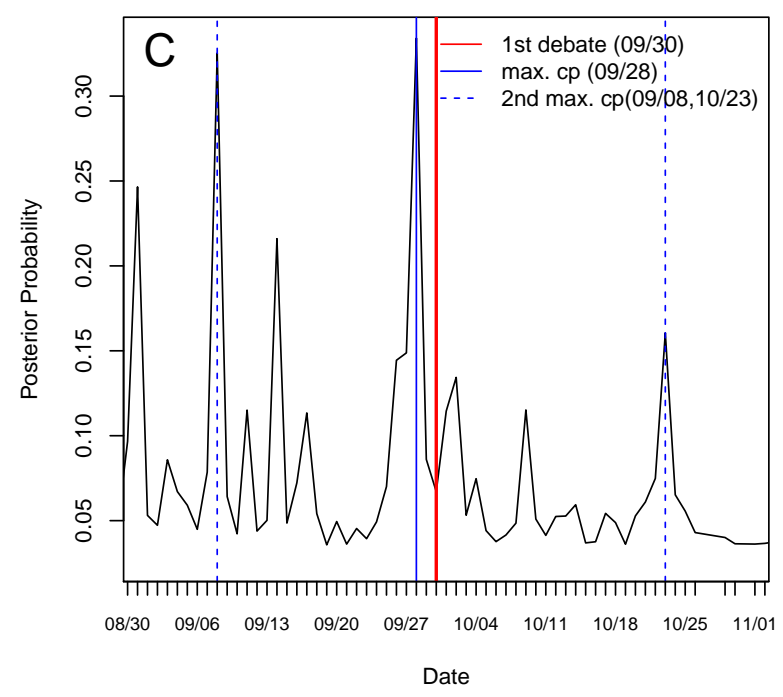

Network Size around the First Debate

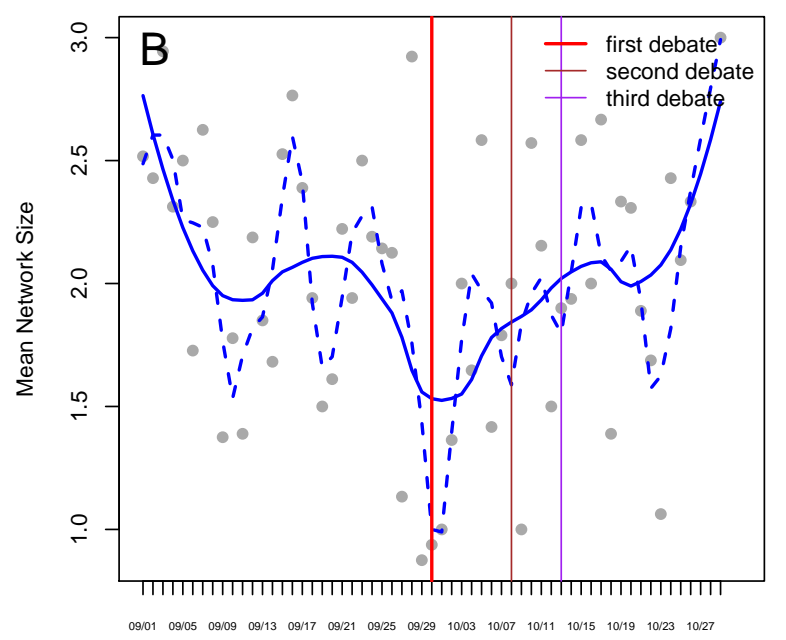

Posterior Mean of Network Size

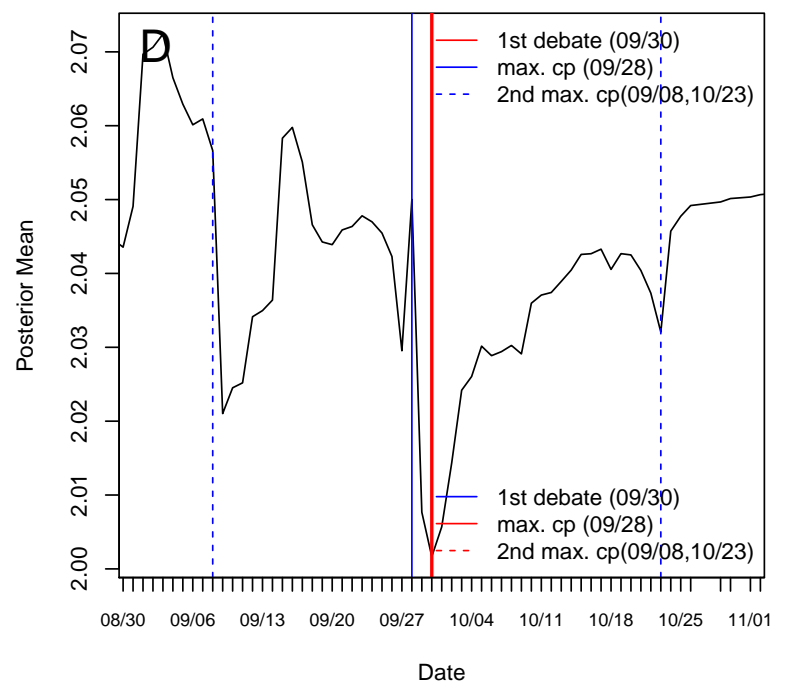

Figure 3: Network variation around the first presidential debate in 2004. Note: In panel A, the number of participants who responded to the network name generator on each survey date is plotted across time. In panel B, each gray dot represents the mean network size per day, and the blue line shows the loess curve (i.e., local regression estimates) estimated by the loess function in $\mathbf{R}$ with the smoothing parameter $(\alpha)$ set to 0.4 (solid line) and 0.15 (dotted line). Estimating the Bayesian change point model (using $b c p$ package in $\mathbf{R}$ ) yields the posterior probability of change points on average network size on each day in panel $C$ and its posterior mean in panel D. The Blue solid line indicates the date (September 28th) that reaches the maximum posterior probability of change point, and the red solid line indicates the date of the presidential debate (September 30th), when we observe the smallest posterior mean network size. Two blue dotted lines show the next largest change points on September 8th and October 23rd. 
three-day moving average $t-1, t, t+1)$-network size for each survey date, plotted as gray dots across time from September to October. The loess curves (i.e., local regression estimators) predicted with two different smoothing parameters in panel B clearly show that network size is smaller when respondents participated in the survey closer to the first presidential debate in 2004 (marked by a red vertical line). Note the V-pattern indicating a precipitous decline and increase in network size for the first debate, which is present (though more muted) for the second and third debates.

Panel $C$ shows the posterior probability of change points, and panel D shows the posterior mean of network sizes from the Bayesian change point model. The maximum posterior probability for a change point is September 28th (colored by the red vertical line). This is right before the first presidential debate (September 8th), colored by the blue vertical line, which is when we observe the smallest posterior mean network size in panel D. The second largest posterior probabilities before and after the debate, indicated by dotted red lines, are September 8th and October 23 rd -22 days and 24 days away from the debate, respectively. Given the next largest change points, we define the maximum width of the caliper as 21 days.

Before testing the significance of the V-pattern, we examine the linearity assumption. Table B3 in the online supplement shows the degree to which linear models lose explanatory power compared to a nonparametric dummy model free of any parametric assumptions because it estimates all effects of each treatment day. We conduct likelihood ratio tests after estimating random-intercept poisson regression models across a range of moving calipers from 1 to 21 , and they confirm the validity of linearity assumption; the linear models do not significantly differ from the dummy models at the $p=0.05$ level. We also evaluate the significance of the linear trend before and after the debate against null distributions from 1,000 simulations that assign respondents to random survey dates, matching the number of observations each day (Figure B1 in the online supplement). In this simulation, respondents retain all of their attributes and characteristics. The only thing that we allow to vary is the timing in which they complete the survey. Each histogram reports for each day the null distributions arising from random arrivals. The solid gray line represents the observed coefficient for the debate effect, and the dotted black line shows the adjusted coefficient after controlling for the key covariates. For statistical comparison, we identify the 95th percentile of the simulated distribution (red lines). The vast majority of both the adjusted and unadjusted coefficients are significant. This confirms that the observed V-pattern is meaningful and not simply statistical noise.

The small gaps between adjusted and unadjusted coefficients shown in Figure B1 across the moving windows imply that survey participation is exogenous to the presidential debate. In English, this means that whatever reason people may have had for participating in the survey on a given day, the day they decided to complete the survey had nothing to do with the debate. Still, we examine the extent of reachability bias by conducting balancing tests on a range of respondents' characteristics, reported in Figure B2 in the online supplement. Figure B2 shows the $t$-statistics for mean differences on a set of pretreatment confounders included in the regression model as well as party identification and partisan strength across 
all moving windows. None of covariates significantly differ across a full range of moving windows from 6 to 21 days, with reference to overall period (panels A and B). In other words, we find that those who were reached within each caliper (= $\mid t_{0}$ - moving window $\left.\mid\right)$ have similar characteristics to those who participated in the survey out of the caliper. The absence of imbalance in balancing tests confirms that the reachability bias is not a concern.

The remaining concern is the presence of other prominent events during the analytic period that could lead to the violation of event exogeneity of the first presidential debate. This is a testable empirical question. Figure B3 in the online supplement shows a full range of regression coefficients from estimating poisson models that change the event date in our treatment indicator $\left(=t_{0}\right)$ for all dates in the fall across a full range of temporal calipers. We find that nearly none of the regression coefficients in other dates during the period around the first debate are larger than the coefficients for the first presidential debate (red horizontal lines) unless the moving window is larger than 16 days. The absence of other events that politically prime people so as to drive declines in reported network size indicates the first presidential debate played a more significant role in the issue-attention cycle than the others during the period ${ }^{9}$. We next turn to identifying the mechanisms that motor the ways in which priming effects lead people to report fewer discussion partners.

\section{Disengagement and the Priming Effect}

Logically, it follows that the priming effect should be absent for people not exposed to the priming event in the first place. The first presidential debate couldn't prime individuals who didn't care about or see it, and as a result, the important matters they discuss should not suddenly become political even if such political events are seemingly widely reported in the mass media. Because people see what they want to see and don't see what they don't want to see, we can assess if this is the case. We know something about the characteristics of individuals that lead them to be more or less politically engaged, and it is this engagement that has to be associated with caring (even a little) about the presidential debate. In Figure 4, we report how individual characteristics salient for political engagement, political interest, and political discussion frequency interact with the priming effect. Panels A and B show that those who are very interested in politics or discuss politics frequently are more sensitive to the priming effect than others. They were probably some of the 62 million people who watched the debate.

\section{Community Polarization and the Priming Effect}

While there is no restriction in the GSS to select discussion partners from ones' neighborhood, it is often the case that recent conversations with people about important matters are with people from ones' community, and to the extent to which this is true, the local context defined by the characteristics of people residing in ego's community plays a role in shaping what people feel comfortable discussing (Mollenhorst, Volker, and Flap 2014). Because most people strive to avoid dissonant or uncomfortable conversations, the presence or absence of ideological segregation 
Political Interests

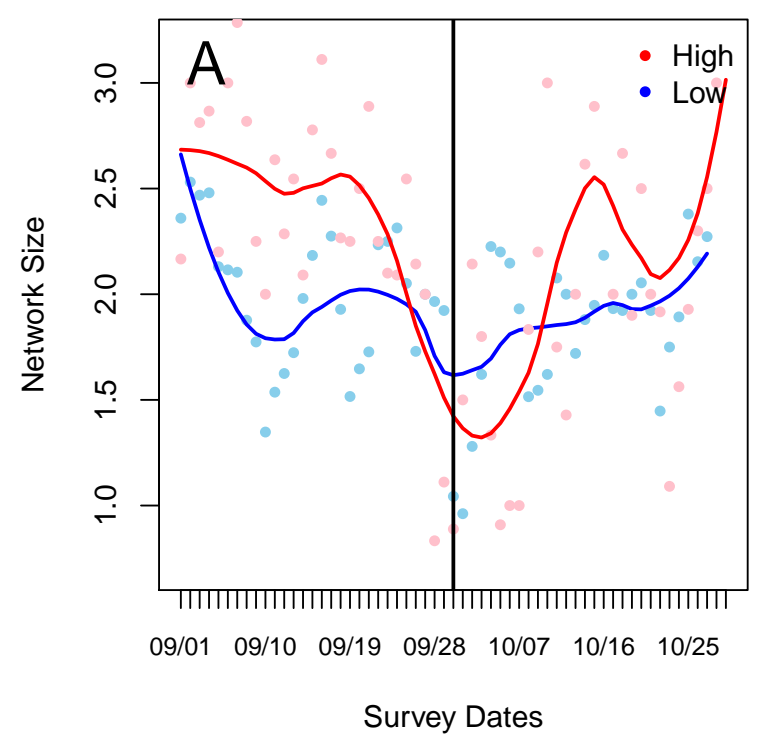

Political Discussion

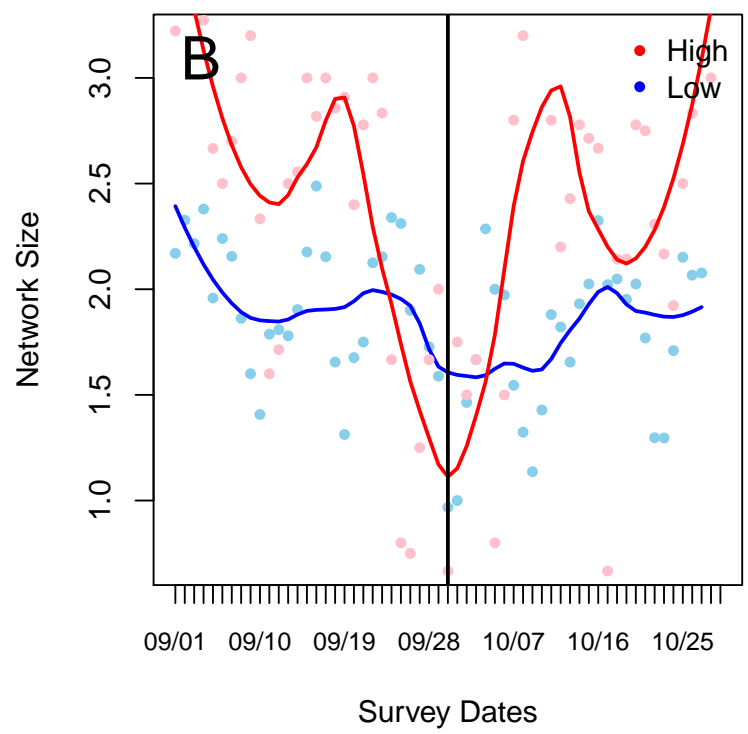

Figure 4: The interaction effects of priming with political engagement at the individual level. Note: Each circle represents the mean network size for the three days around each survey date $(t-1, t, t+1)$, and each line shows the loess curve estimated by the loess function in $\mathbf{R}$ package with smoothing parameter $(\alpha)$ set to 0.4 depending on each category; Political Interest is dichotomized into High (very interested) and Low (rest); Political Discussion is dichotomized into High (discuss politics often) and Low (rest).

in the local environment provides an efficient description of the context in which such conversations can occur. It also provides us with an opportunity to construct a risky test of our theory in a different context: if we are right that people will try to avoid dissonant conversations when they are primed to think about important matters as political matters, then it should be the case that reported discussion networks are smaller in less polarized communities. This follows because in nonpolarized communities, the chances are greater than in polarized communities that one might talk to someone whose views differ.

Figure 5, panels A-C report distributions of these variables. Consistent with our expectation, Figure 5, panels D-E show that those who live in low-polarized PSUs-across all three measures-report smaller networks around the first presidential debate. However, those who live in high-polarized PSUs consistently report similarly sized network across time. Initially, this would appear counterintuitive. But reflection indicates it is not. Our discussion networks are composed of people who are like us. In polarized communities, Democrats talk to Democrats and Republicans talk to Republicans about important matters. Priming that turns important matters into political matters has little effect because they already know that they agree. Their neighborhoods and their networks are polarized politically already. In nonpolarized neighborhoods, this is not the case. Democrats may well talk about important matters with Republicans. Because polarization is absent, political 

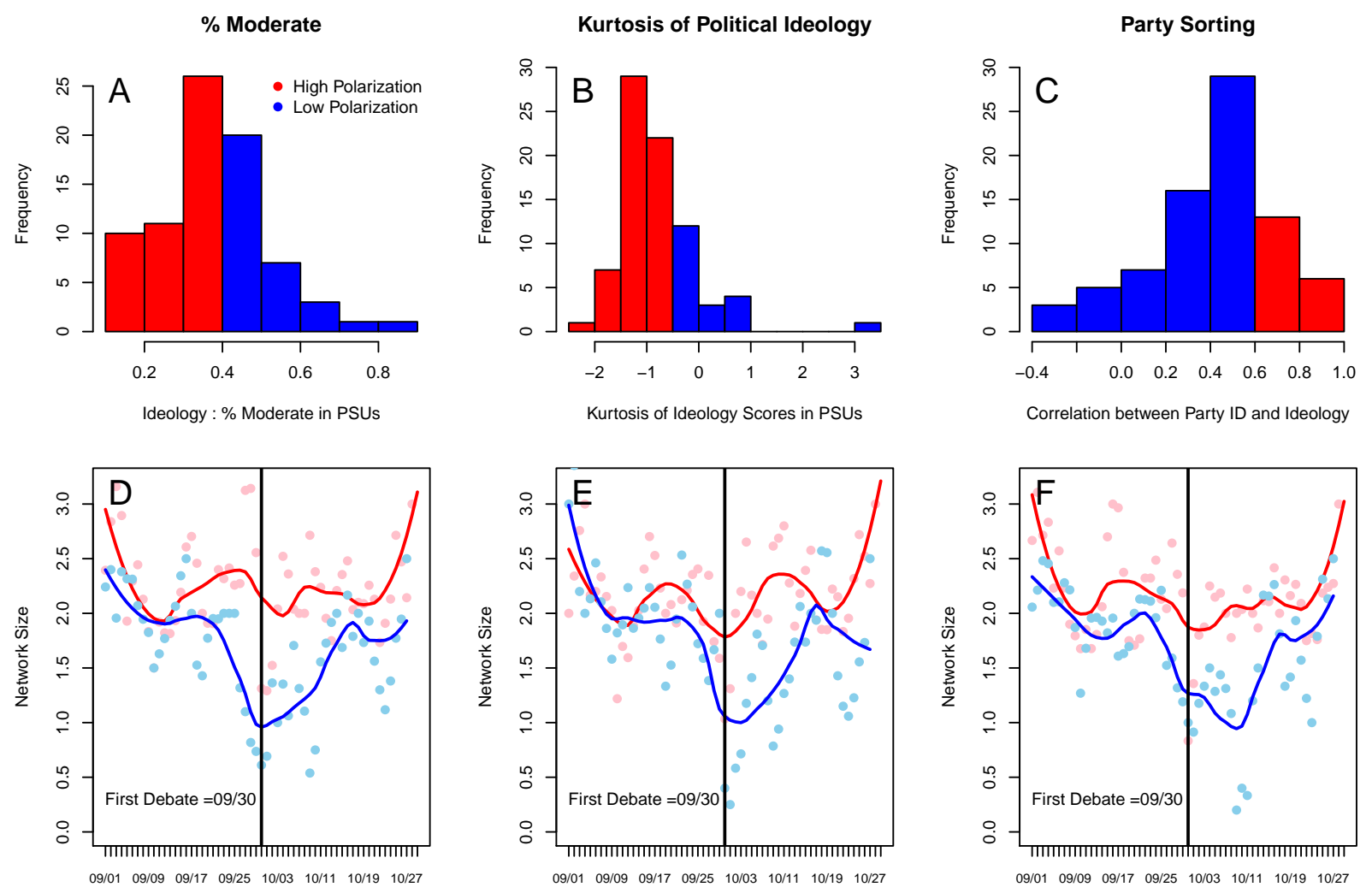

Figure 5: Priming and spatial political polarization in 2004. Note: We measure political polarization in each PSU (sampcode) in three different ways and plot their distribution. Panel A reports the proportion of moderate respondents, panel B reports the kurtosis of political ideology, and the correlation coefficient between party identification and political ideology is reported in panel C. We dichotomize each measure based on its mean value and plot the mean network size per day as differently colored circles by level of polarization: low (blue) and high (red). As in Figure 4, the smoothed means for network size are plotted as sky blue or pink circles-depending on the level of political polarization — with the loess curves overlaid.

beliefs are not salient in choosing discussion partners. But a priming event that reframes "important matters" to "political matters" makes a difference for people in nonpolarized communities. Suddenly, the important matter is a political matter, and the conversation that can occur is fraught with potential danger. In response, people talk to fewer people, which reduces the size of their discussion network.

So far, our theory has survived two reasonable risky tests. We show that there really were smaller networks in 2004, and those smaller networks arose for a very specific reason: respondents were primed to think about political (rather than important) matters and answered interviewer questions with that framework in mind. 


\section{Discussion}

Do Americans have fewer close confidents with whom they talk about important matters than they did in the 1980s? The most robust evidence that they do is found in the 2004 GSS, which reported seemingly inexplicable declines in the size of our closest interpersonal networks (McPherson et al. 2006). Because the causes of this change were largely unexplained in the original article, and because none of the factors thought to shape network size changed sufficiently to account for the observed decrease, scholars have eagerly searched for the supposed methodological smoking gun that invalidates the survey. This article suggests that they have been largely unsuccessful ${ }^{10}$ —that there is "nothing wrong" with the 2004 GSS network instrument or the findings arising from it. At the same time, this article shows that we cannot make inferences about social change from those results because they are not comparable to earlier or later GSS social network surveys. In this regard, there is a smoking gun. The "gun" is time, the "bullet" is priming.

For a couple of weeks in the middle of the field period, Americans really talked to fewer people about "important matters" because the first presidential debate and the entire presidential election period primed respondents to think that "important matters" were "political matters" and eschewed potentially conflictual conversations. Nothing like that happened before or after, because no previous General Social Survey with a battery of network questions was conducted in the fall of a presidential election year.

Scholars agree that there is increased political polarization in the United States (Abramowitz and Saunders 2008; Baldassarri and Gelman 2008; Baldassarri and Goldberg 2014; Fiorina and Abrams 2008; Prior 2013). Talking about politics is potentially uncomfortable when polarization is marked, especially in highly polarized contexts, in which the attitudes of others may not be known (Cowan and Baldassarri 2016). If this is the case, it follows that nonpartisans should have fewer discussion partners when they think that the important matters of the day are political matters. This is not the case for partisans. While their networks may become somewhat smaller, they can still easily have conversations with partisan friends whose opinions on politics they are sure of and which concord with their own. Against this background, many Americans are at risk of "political isolation." In such a situation, our capacity to have a meaningful public discourse about politics may be significantly lessened.

There is some additional evidence to support this idea. During the fall of the 2016 U.S. presidential election, widely thought to be the nastiest and most partisan to date, we collected network size data using the "important matters" and "political matters" network name generators from 1,055 American adults using the Time Sharing Experiment for Social Sciences (TESS) platform ${ }^{11}$. Our results show that the average reported discussion network size is very small (1.4). As we have tried to argue, this does not mean that Americans are more isolated than ever before. But it does mean that Americans are politically isolated-they really do have fewer people that they talk to about political matters. While the link between this fact and the hollowing out of substantive content in politics is speculative, it is, we believe, a speculation worth considering. 
For a long time, we have known that the "important matters" name generator is sensitive to survey context. If the network battery followed questions about education, for example, people would report that their last important conversation was about education (Bailey and Marsden 1999)! But what we never considered was how temporal context shapes how the important matters name generator works ${ }^{12}$. This article shows that temporal context, identified more than 40 years ago by Anthony Downs as driven by issue-attention cycles, is absolutely critical for that understanding. In the fall of 2004, around the first presidential debate, respondents were primed to think about politics when they thought about important matters, and when they did, they reported talking to fewer people than ever before. This was especially true for people living in communities characterized by greater structural opportunity to talk with diverse others with respect to political beliefs.

More than 60 million Americans watched the first presidential debate in 2004. The people who watched the debate cared more about politics than those who did not (Kenski and Stroud 2005). The run-up to the debate and the discussion that followed it dominated other issues competing for attention at the end of September 2004, and so it follows that if the priming mechanism we identify as shifting focus from important to political matters operates, it should impact those more interested in politics than those less interested. We show that this is the case. The strikingly steep decline in network size for just a few weeks around the first presidential debate is real, but it is momentary. The short-lived nature of priming effects reflects the limited attention space in people's minds as well as the public arena (Hilgartner and Bosk 1988). What can we learn from that fact?

One thing we can learn is methodological. There is a whole body of very good scholarship that has concentrated on developing a variety of statistical methods to analyze panel data with a focus on how individual responses vary from panel to panel (Morgan and Winship 2014; Rabe-Hesketh and Skrondal 2012), all the while assuming that responses within each panel are constant. The results of this article show that this assumption is not warranted. It tells us that we need to pay much more attention to the role of the temporal (unobserved) heterogeneity in the identification of causal effects and estimation of population parameters, whether or not one has a representative sample. Other work has contributed to this demonstration as well. For example, terrorist attacks that happened during survey fieldwork shape survey respondents' attitudes toward immigrants (Legewie 2013) and fans of winning basketball teams in the 2009 NCAA men's college basketball tournament rated President Obama's job performance more positively after they won than before (Healy, Malhotra, and Mo 2010). Temporal context gets under the skin of surveys. In our case, temporal context shapes the ways in which people interpret questions they are asked (Jerolmack and Khan 2014). This changes, necessarily, the answers that they give.

We live in the world of replication crisis. It is easy to find some statistically significant effects just by chance, though it is hard to replicate the same effects (Lee and Conley 2016; Open Science Collaboration 2015). The solution to this problem is to secure more precision in the identification of causal mechanisms in addition to the identification of causal estimates. In this article, we believe we have identified the precise mechanism that led to decreased network size in 2004. That we see the 
trace of the same process in our data from 2016 is both reassuring with respect to our argument and deeply distressing with respect to the prospects for meaningful conversation about important political matters and the rise of political isolation.

\section{Notes}

1 For example, Bearman and Parigi (2004) said "at the time of our data collection, stories concerned the "nanny" in Boston who murdered her charge, a state trooper who was shot on interstate 95, road construction projects, moral issues in the Clinton White House, and trouble in the livestock (specifically pig) industry . . . were frequently discussed" (p. 537).

2 The literature on political polarization is split into those who see mass polarization (i.e., the opinion distribution of the electorate has become more extreme and bimodal) (Abramowitz and Saunders 2008) and those who see party sorting (i.e., the opinion distribution remains unimodal, but the alignment of partisanship and ideology has become tighter) (Fiorina and Abrams 2008). For our purposes, this does not matter because the interpersonal network effects downstream are the same for both models.

3 Note that our goal in this exercise is not to investigate the entire space for all different (issue) domains but to illustrate the short-lived nature of the issue-attention cycle using some selected examples. Of course there are many issues that don't take off while other issues compete with one another at the same time. We address these points in panel $\mathrm{B}$, which tracks the relative level of public attention to "political matters" within the political domain over time.

4 We focus on the priming effects of the first presidential debate rather than the presidential election in this study because only a few individuals were surveyed for the 2004 GSS survey around November 1 st.

5 While Klofstad, McClurg, and Rolfe (2009) argue that the network characteristics reported from these two name generators are not statistically different, the political matters name generator consistently yields fewer names than the important matters name generator. It is worth observing, however, that the data (the 1996-1997 Indianapolis-St. Louis Study) they used contain numerous political survey items that could have primed respondents so as to frame important matters as political matters. Sokhey and Djupe (2014) also reported smaller network size from the political matters name generator.

6 The fact that the first presidential debate in 2004 took place around the acute change point supported by the predictive model does tell how long its effects will persist within the maximum caliper compared to the counterfactual situation of its absence. For example, if we assume that the debate will suppress the core discussion network linearly for a week, then the linear treatment indicator will have an effect among respondents who participate in the survey within a week before and after the debate but not within two weeks.

7 Following Baldassarri and Bearman (2007)'s strategy, we compute the kurtosis-which captures the bimodality of distribution-as kurtosis $s_{j}=\frac{\sum_{i=1}^{N}\left(p_{i}-\mu_{j}\right)^{4}}{N \sigma_{j}^{4}}-3$, where $p_{i}$ is an individual $i$ 's political ideology score, $\mu_{j}$ and $\sigma_{j}$ are the mean and the standard deviation of political ideology in the neighborhood $j$, and $N$ is the number of individuals in neighborhood $j$.

8 Normally one would measure polarization using the political ideology battery in the GSS, but the 2004 GSS did not collect political ideology information for those who responded to the network name generator. 
9 Logically, and probably empirically as well, the election would have primed in the same manner, but the small $N$ of respondents in the days immediately before and after the election means that inferences about around the election are unreliable.

10 It is worth observing that while the prior attempts to identify why Americans reported having smaller networks in 2004 than at any other time were largely unsuccessful, many of the articles had the intuition that political events during the survey period may have played a role. For example, McPherson et al. (2006) stated: “What American considered important might well have shifted over the past two decades, perhaps as a result of major events . . . If people think of 'important' more in terms of national and world-level events, more people might now think that they have nothing important to say" (p. 372). Likewise, Fischer (2009) wrote: "One might speculate, for example, that being questioned during a spring [sic] full of heated discussion about war and presidential primaries may have led many respondents to interpret 'important matters' as political matters" (p. 668).

11 This result comes from analysis of data arising from a survey experiment entitled, "Networks in Time: Testing Contextual Effects in the 2004 General Social Survey Network Items."

12 Of course, there is a body of scholarship that studies the sensitivity of the recall period (i.e., "the last six months") in network name generators (Sokhey and Djupe 2014) as well as change in core discussion networks across individual life trajectories (Mollenhorst et al. 2014; Small et al. 2015). However, neither approach treats temporal context as a situational structure constituted by real-time events that shape individuals' action frameworks.

\section{References}

Abramowitz, Alan I., and Kyle L. Saunders. 2008. "Is Polarization a Myth?" The Journal of Politics 70(2):542-555. https: /doi .org/10.1017/S0022381608080493

Bailey, Stefanie, and Peter V. Marsden. 1999. “Interpretation and Interview Context: Examining the General Social Survey Name Generator Using Cognitive Methods." Social Networks 21(3):287-309. https : /doi .org/10.1016/S0378-8733(99)00013-1

Baldassarri, Delia, and Peter Bearman. 2007. "Dynamics of Political Polarization." American Sociological Review 72(5):784-811. https : /doi .org/10.1177/000312240707200507

Baldassarri, Delia, and Andrew Gelman. 2008. "Partisans without Constraint: Political Polarization and Trends in American Public Opinion." American Journal of Sociology 114(2):408-46. https : /doi .org/10.1086/590649

Baldassarri, Delia, and Amir Goldberg. 2014. "Neither Ideologues, nor Agnostics: Alternative Voters' Belief System in an Age of Partisan Politics." American Journal of Sociology 120(1): 45-95. https:/doi.org/10.1086/676042

Barry, Daniel, and J. A. Hartigan. 1993. "A Bayesian Analysis for Change Point Problems." Journal of the American Statistical Association 88(421):309-19.

Bearman, Peter, and Paolo Parigi. 2004. "Cloning Headless Frogs and Other Important Matters: Conversation Topics and Network Structure." Social Forces 83(2):535-57. https : /doi.org/10.1353/sof.2005.0001

Benoit, William L., Glenn J. Hansen, and Rebecca M. Verser. 2003. "A Meta-Analysis of the Effects of Viewing U.S. Presidential Debates." Communication Monographs 70(4):335-50. https:/doi.org/10.1080/0363775032000179133 
Brashears, Matthew. 2014. "'Trivial' Topics and Rich Ties: The Relationship Between Discussion Topic, Alter Role, and Resource Availability Using the 'Important Matters' Name Generator." Sociological Science 1:493-511. https : /doi .org/10.15195/v1 . a27

Brashears, Matthew E. 2011. "Small Networks and High Isolation? A Reexamination of American Discussion Networks." Social Networks 33(4):331-41. https:/doi.org/10. 1016/j.socnet.2011.10.003 https:/doi.org/10.1016/j.socnet.2011.10.003

Burt, Ronald S. 1984. "Network Items and the General Social Survey." Social Networks 6(4):293339. https:/doi.org/10.1016/0378-8733(84)90007-8

Cowan, Sarah, and Delia Baldassarri. 2016. "It Could Turn Ugly: Selective Disclosure of Political Views and Biased Network Perception." Working Paper.

Downs, A. 1972. “Up and down with Ecology: The Issue-Attention Cycle." Public Interest 28:50.

Eagle, David E., and Rae Jean Proeschold-Bell. 2015. "Methodological Considerations in the Use of Name Generators and Interpreters." Social Networks 40:75-83. https: /doi.org/10.1016/j.socnet.2014.07.005

Erdman, Chandra, and John W. Emerson. 2007. “Bcp: An R Package for Performing a Bayesian Analysis of Change Point Problems." Journal of Statistical Software 23(3):1-13. https:/doi.org/10.18637/jss.v023.i03

Fiorina, Morris P., and Samuel J. Abrams. 2008. "Political Polarization in the American Public." Annual Review of Political Science 11(1):563-88. https : /doi . org/10.1146/annurev . polisci.11.053106.153836

Fischer, Claude S. 1982. To Dwell Among Friends: Personal Networks in Town and City. University of Chicago Press.

Fischer, Claude S. 2009. "The 2004 GSS Finding of Shrunken Social Networks: An Artifact?" American Sociological Review 74(4):657-69. https:/doi.org/10.1177/ 000312240907400408

Fischer, Claude S. 2012. "The Loneliness Scare Is Back." Made in America: A Social History of American Culture and Character Blog. Retrieved November 28, 2015 https://madeinamericathebook.wordpress.com/2012/04/24/ the-loneliness-scare-is-back/.

Fischer, Claude S., and Greggor Mattson. 2009. "Is America Fragmenting?" Annual Review of Sociology 35(1):435-55. https : /doi .org/10 .1146/annurev-soc-070308-115909

Gamson, William A., Bruce Fireman, and Steven Rytina. 1982. Encounters with Unjust Authority. Dorsey Press.

Gerber, Alan S., Gregory A. Huber, David Doherty, and Conor M. Dowling. 2012. “Disagreement and the Avoidance of Political Discussion: Aggregate Relationships and Differences across Personality Traits." American Journal of Political Science 56(4):849-874. https:/doi.org/10.1111/j.1540-5907.2011.00571.x

Hampton, Keith N., and Richard Ling. 2013. "Explaining Communication Displacement and Large-Scale Social Change in Core Networks." Information, Communication and Society 16(4):561-89. https:/doi.org/10.1080/1369118X.2013.777760

Hampton, Keith N., Lauren F. Sessions, and Eun Ja Her. 2011. “Core Networks, Social Isolation, and New Media." Information, Communication and Society 14(1):130-55. https : /doi.org/10.1080/1369118X.2010.513417

Healy, Andrew J., Neil Malhotra, and Cecilia Hyunjung Mo. 2010. "Irrelevant Events Affect Voters' Evaluations of Government Performance." Proceedings of the National Academy of Sciences 107(29):12804-9. https : /doi .org/10.1073/pnas . 1007420107 
Hilgartner, Stephen, and Charles L. Bosk. 1988. "The Rise and Fall of Social Problems: A Public Arenas Model." American Journal of Sociology 94(1):53-78. https:/doi.org/10. $1086 / 228951$

Hoffman, Mark, and Peter Bearman. 2015. “Bringing Anomie Back In: Exceptional Events and Excess Suicide." Sociological Science 2:186-210. https : /doi .org/10.15195/v2 . a10

Huckfeldt, Robert, Paul E. Johnson, and John Sprague. 2004. Political Disagreement: The Survival of Diverse Opinions Within Communication Networks. Cambridge University Press. https:/doi.org/10.1017/CB09780511617102

Huckfeldt, Robert, and John Sprague. 1987. "Networks in Context: The Social Flow of Political Information." The American Political Science Review 81(4):1197-1216. https: /doi.org/10.2307/1962585

Huckfeldt, Robert, and John Sprague. 1988. "Choice, Social Structure, and Political Information: The Information Coercion of Minorities." American Journal of Political Science 32(2):467-82. https : /doi .org/10.2307/2111132

Jerolmack, Colin, and Shamus Khan. 2014. "Talk Is Cheap: Ethnography and the Attitudinal Fallacy." Sociological Methods and Research 43(2):178-209. https:/doi.org/10.1177/ 0049124114523396

Kenski, Kate, and Natalie Jomini Stroud. 2005. "Who Watches Presidential Debates? A Comparative Analysis of Presidential Debate Viewing in 2000 and 2004." American Behavioral Scientist 49(2):213-28. https : /doi .org/10.1177/0002764205279423

Klofstad, Casey A., Scott D. McClurg, and Meredith Rolfe. 2009. "Measurement of Political Discussion Networks A Comparison of Two 'Name Generator' Procedures." Public Opinion Quarterly 73(3):462-83. https:/doi.org/10.1093/poq/nfp032

Lee, Byungkyu, and Dalton Conley. 2016. “Does the Gender of Offspring Affect Parental Political Orientation?" Social Forces 94(3):1103-27. https : /doi .org/10.1093/sf/sov098

Legewie, Joscha. 2013. "Terrorist Events and Attitudes toward Immigrants: A Natural Experiment." American Journal of Sociology 118(5):1199-1245. https : /doi .org/10 . 1086/ 669605

Marin, Alexandra. 2004. "Are Respondents More Likely to List Alters with Certain Characteristics?: Implications for Name Generator Data." Social Networks 26(4):289-307. https:/doi.org/10.1016/j.socnet.2004.06.001

Marsden, Peter V. 1987. “Core Discussion Networks of Americans." American Sociological Review 52(1):122-31. https: /doi .org/10.2307/2095397

Marsden, Peter V., and Sameer B. Srivastava. 2012. "Trends in Informal Social Participation, 1974-2008." in Social Trends in American Life: Findings from the General Social Survey since 1972, edited by P. V. Marsden. Princeton University Press.

McPherson, Miller, Lynn Smith-Lovin, and Matthew E. Brashears. 2006. "Social Isolation in America: Changes in Core Discussion Networks over Two Decades." American Sociological Review 71(3):353-75. https : /doi .org/10.1177/000312240607100301

McPherson, Miller, Lynn Smith-Lovin, and Matthew E. Brashears. 2009. "Models and Marginals: Using Survey Evidence to Study Social Networks." American Sociological Review 74(4):670-81. https:/doi.org/10.1177/000312240907400409

Mollenhorst, Gerald, Beate Völker, and Henk Flap. 2008. "Social Contexts and Core Discussion Networks: Using a Choice Approach to Study Similarity in Intimate Relationships." Social Forces 86(3):937-65. https : /doi .org/10.1353/sof .0.0010

Mollenhorst, Gerald, Beate Völker, and Henk Flap. 2014. "Changes in Personal Relationships: How Social Contexts Affect the Emergence and Discontinuation of Relationships." Social Networks 37:65-80. https:/doi . org/10.1016/j. socnet.2013.12.003 
Morgan, Stephen L., and Christopher Winship. 2014. Counterfactuals and Causal Inference. Cambridge University Press. https:/doi.org/10.1017/CB09781107587991

Open Science Collaboration. 2015. "Estimating the Reproducibility of Psychological Science." Science 349(6251).

Paik, Anthony, and Kenneth Sanchagrin. 2013. "Social Isolation in America: An Artifact." American Sociological Review 78(3):339-60. https: /doi .org/10.1177/0003122413482919

Parigi, Paolo, and Warner Henson. 2014. "Social Isolation in America." Annual Review of Sociology 40(1):153-71. https : /doi . org/10.1146/annurev-soc-071312-145646

Paxton, Pamela. 1999. "Is Social Capital Declining in the United States? A Multiple Indicator Assessment." American Journal of Sociology 105(1):88-127. https:/doi.org/10.1086/ 210268

Prior, Markus. 2013. "Media and Political Polarization." Annual Review of Political Science 16(1):101-27. https: /doi .org/10.1146/annurev-polisci-100711-135242

Putnam, Robert D. 2000. Bowling Alone: The Collapse and Revival of American Community. Simon and Schuster. https:/doi.org/10.1145/358916.361990

Rabe-Hesketh, Sophia, and Anders Skrondal. 2012. Multilevel and Longitudinal Modeling Using Stata, Volumes I and II, Third Edition. 3 edition. College Station, Tex: Stata Press.

Rytina, Steve, and David L. Morgan. 1982. "The Arithmetic of Social Relations: The Interplay of Category and Network." American Journal of Sociology 88(1):88-113. https:/doi .org/ $10.1086 / 227635$

Schwadel, Philip, and Michael Stout. 2012. "Age, Period and Cohort Effects On Social Capital." Social Forces 91(1):233-52. https : /doi .org/10.1093/sf/sos062

Sigman, Aric. 2009. “Well Connected?" Biologist 56(1):14-20.

Small, Mario Luis. 2013. "Weak Ties and the Core Discussion Network: Why People Regularly Discuss Important Matters with Unimportant Alters." Social Networks 35(3):47083. https:/doi.org/10.1016/j. socnet.2013.05.004

Small, Mario Luis, Vontrese Deeds Pamphile, and Peter McMahan. 2015. "How Stable Is the Core Discussion Network?" Social Networks 40:90-102. https:/doi .org/10.1016/j . socnet.2014.09.001

Smith, Jeffrey A., Miller McPherson, and Lynn Smith-Lovin. 2014. "Social Distance in the United States Sex, Race, Religion, Age, and Education Homophily among Confidants, 1985 to 2004." American Sociological Review 79(3):432-56. https:/doi .org/10.1177/ 0003122414531776

Sokhey, Anand E., and Paul A. Djupe. 2014. "Name Generation in Interpersonal Political Network Data: Results from a Series of Experiments." Social Networks 36:147-61. https : /doi.org/10.1016/j.socnet.2013.02.002

Straits, Bruce C. 2000. “Ego's Important Discussants or Significant People: An Experiment in Varying the Wording of Personal Network Name Generators." Social Networks 22(2):12340. https:/doi.org/10.1016/S0378-8733(00)00018-6

Wang, Hua, and Barry Wellman. 2010. "Social Connectivity in America: Changes in Adult Friendship Network Size From 2002 to 2007." American Behavioral Scientist 53(8):1148-69. https:/doi.org/10.1177/0002764209356247

Wellman, Barry. 1979. “The Community Question: The Intimate Networks of East Yorkers." American Journal of Sociology 84(5):1201-31. https : /doi . org/10 .1086/226906

Zhao, Shanyang. 2006. “Do Internet Users Have More Social Ties? A Call for Differentiated Analyses of Internet Use." Journal of Computer-Mediated Communication 11(3):844-62. https:/doi.org/10.1111/j.1083-6101.2006.00038.x 
Zuckerman, Alan S. 2005. The Social Logic of Politics: Personal Networks as Contexts for Political Behavior. Temple University Press.

Acknowledgements: We benefitted from comments from Delia Baldassarri, Philipp Brandt, Hannah Bruckner, Wooseok Jung, Shamus Khan, Dohoon Lee, Kinga Makovi, James Moody, Chris Muller, Barum Park, Adam Reich, Eun Kyong Shin, Yunkyu Sohn, and Robb Willer. An earlier version of this article was presented at the 9th International Network of Analytical Sociology conference. Support from the Interdisciplinary Center for Innovative Theory and Empirics (INCITE) at Columbia University is gratefully acknowledged. Please direct all correspondence to Peter Bearman (psb17@columbia.edu). Replication materials to reproduce all Figures and Tables are available at https://dataverse.harvard.edu/dataverse/bk.

Byungkyu Lee: Department of Sociology, Columbia University.

E-mail: bl2474@columbia.edu.

Peter Bearman: INCITE, Columbia University.

E-mail: psb17@columbia.edu. 